\title{
Morphology of the corpus callosum at different stages of schizophrenia: cross-sectional study in first-episode and chronic illness
}

\author{
Mark Walterfang, Amanda G. Wood, David C. Reutens, Stephen J. Wood, Jian Chen, \\ Dennis Velakoulis, Patrick D. McGorry and Christos Pantelis
}

\section{Background}

The shape of the corpus callosum may differ in schizophrenia, although no study has compared first-episode with established illness.

\begin{abstract}
Aims
To investigate the size and shape of the corpus callosum in a large sample of people with first-episode and established schizophrenia.

Method

Callosal size and shape were determined using highresolution magnetic resonance imaging on 76 patients with first-episode schizophrenia-spectrum disorders, 86 patients with established schizophrenia and 55 healthy participants.
\end{abstract}

\section{Results}

There were no significant differences in total area across groups. Reductions in callosal width were seen in the region of the anterior genu in first-episode disorder $(P<0.005)$. Similar reductions were seen in the chronic schizophrenia group in the anterior genu, but also in the posterior genu and isthmus $(P=0.0005)$

\section{Conclusions}

Reductions in anterior callosal regions connecting frontal cortex are present at the onset of schizophrenia, and in established illness are accompanied by changes in other regions of the callosum connecting cingulate, temporal and parietal cortices

\section{Declaration of interest}

None. Funding detailed in Acknowledgements.
The corpus callosum has been strongly implicated as an anatomical mediator of dysfunctional inter-hemispheric transfer in schizophrenia, ${ }^{1}$ and anomalies of the corpus callosum are found more commonly in people with schizophrenia than the general population. ${ }^{2}$ The first magnetic resonance imaging (MRI) study suggested alterations in its size and shape in schizophrenia. ${ }^{3}$ Subsequent analyses have found conflicting results, including global increases, ${ }^{3,4}$ reductions ${ }^{5,6}$ or no differences ${ }^{7,8}$ compared with healthy individuals, although a meta-analysis of the first decade of studies suggests this structure is smaller in patients than in controls. ${ }^{9}$ Data from people experiencing their first episode of schizophrenia suggest that the corpus callosum may also be smaller than in healthy individuals. ${ }^{5,10}$

The aim of the present MRI study was to determine whether the measures of callosal size and shape in a large cohort $(n=217)$ of individuals across differing illness stages (first-episode schizophrenia-spectrum disorders and established illness) differed from that of controls. Based on previous work we hypothesised that patients with established illness would show a globally smaller corpus callosum and reductions in regions connecting frontal and temporal regions, with patients with first-episode schizophreniaspectrum disorders exhibiting similar reductions.

\section{Method}

\section{Participants}

All participants with first-episode schizophrenia-spectrum disorders, aged between 16 and 30 years, were recruited from the Early Psychosis Prevention and Intervention Centre (EPPIC; $n=76)$ and participants with chronic schizophrenia from inpatient and community mental health settings $(n=86)$ within the North Western Mental Health Program, Melbourne, Australia. The DSM-III- $\mathrm{R}^{11}$ diagnoses were based on chart review and structured diagnostic interviews. ${ }^{12,13}$ Control participants $(n=55)$ from similar socio-demographic areas as the patients were recruited from ancillary hospital staff and through advertisements. Demographic data were obtained for all participants (see online data supplement Table DS1). Inclusion criteria for participants in the first-episode schizophrenia-spectrum group ('first-episode group', which included patients with schizophrenia $(n=30)$, schizophreniform disorder $(n=31)$ and schizoaffective disorder $(n=15))$, established illness group and for controls, recruited from 1994 to 1999 , have been previously described. ${ }^{14}$ Patients in the established illness and first-episode groups were rated on the total positive and negative symptoms scales on the Positive and Negative Syndrome Scale (PANSS) ${ }^{15}$ by trained raters, and medication at the time of scanning was converted to chlorpromazine equivalents.

Participants were screened for comorbid medical and psychiatric conditions by clinical assessment, and physical and neurological examination. Written informed consent was obtained from all participants. The study was approved by the local Research and Ethics Committee. Exclusion criteria for patients were: a history of significant head injury, seizures, neurological diseases, impaired thyroid function, steroid use or DSM-III-R criteria of alcohol or substance dependence. Controls with a personal history of psychiatric illness or family history of psychosis were excluded.

\section{Magnetic resonance scanning acquisition and analysis}

All participants were scanned on a 1.5 T GE Signa MRI machine. A three-dimensional volumetric spoiled gradient recalled echo in the steady state sequence generated 124 contiguous, $1.5 \mathrm{~mm}$ coronal slices. Imaging parameters were: time-to-echo (TE), $3.3 \mathrm{~ms}$; time-to-repetition (TR), $14.3 \mathrm{~ms}$; flip angle, $30^{\circ}$; matrix size, $256 \times 256$; field of view (FOV), $24 \times 24 \mathrm{~cm}$ matrix; voxel 
dimensions, $0.938 \times 0.938 \times 1.5 \mathrm{~mm}$. Head movement was minimised by foam padding and straps across the forehead and chin. This scanner was calibrated fortnightly using the same proprietary phantom to ensure stability and accuracy of measurements. A numerical code was used to ensure masked analysis of data.

The brain was automatically segmented from the rest of the head. ${ }^{16}$ Using the software package Automated Image Registration (Red Hat Linux V9), ${ }^{17}$ images were registered to a template image comprising the average of 152 normal $\mathrm{T}_{1}$-weighted MRI scans previously placed in stereotaxic coordinate space. A nine-parameter linear transformation was used which allowed translation, rotation and scaling along each of the three principal axes. The midsagittal slice was identified and interpolated to a voxel dimension of $0.5 \mathrm{~mm} \times 0.5 \mathrm{~mm}$ in the $y$ - and $z$-planes. White matter voxels in the midsagittal slice were identified using a histogram segmentation procedure. ${ }^{18}$ Non-callosal voxels were then removed manually. A measure of callosal area in total $\mathrm{mm}^{2}$ was then generated. To measure regional callosal thickness, voxels at the edge of the callosum were identified, and upper and lower edges were defined according to anterior and posterior endpoints. An iterative search for optimum endpoints which maximised the length of a line segment traversing the centre of the callosum was then performed (Fig. 1). The line segment was defined by dividing the upper and lower surfaces of the callosum into 40 equidistant portions by 39 nodes. The midpoints between corresponding nodes on the upper and lower surfaces were identified. The line segment was created by joining endpoints and successive midpoints. Once the optimum endpoints and corresponding midpoints were identified, a smooth curve joining them was obtained with cubic spline interpolation. This curve was divided into 40 segments of equal lengths by 39 nodes. At each node, the line orthogonal to the curve was calculated. The distance between its intersection with the dorsal and ventral surfaces of the callosum represented regional callosal thickness at these 39 points; the average of these thicknesses represented mean callosal thickness (Fig. 1).

\section{Statistical analysis}

Five analyses were undertaken on the four callosal measures of total callosal area and regional callosal thickness:

(a) comparison of main patient groups: first-episode, established illness and controls

(b) comparison of first-episode psychosis subgroups and controls

(c) analysis of effect of age on patients with established illness and controls, and duration of illness on patients with established illness

(d) analysis of the relationship between medication and callosal measures.

(e) analysis of the relationship between psychotic symptoms and callosal measures.

Determination of the effects of demographic variables was undertaken with chi-square analyses for gender and one-way analysis of variance (ANOVA) with Tukey's post hoc comparison for age in years, height in centimetres and premorbid IQ measured using the National Adult Reading Test. ${ }^{19}$ Positive and negative symptom scales on the PANSS were compared using ANOVA for three-group comparisons and $t$-tests for two-group comparisons. Callosal area was compared between groups using ANOVA. For regional callosal thickness, a non-parametric permutation method $^{20}$ of 10000 randomisations was used for group comparisons to account for non-independence between adjacent thickness measurements and for multiple comparisons; step-down tests were used to localise at which slices the thickness differed

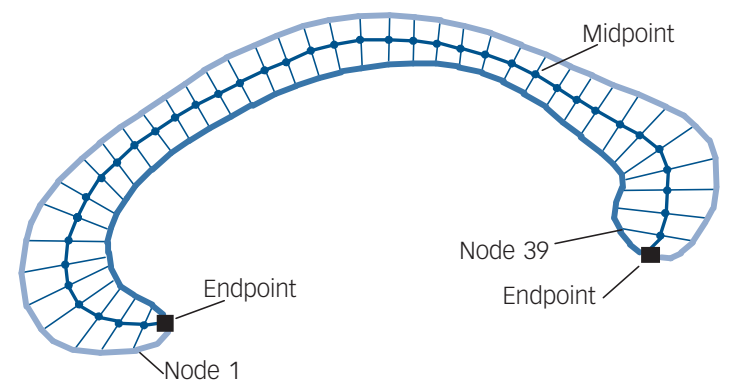

Fig. 1 Endpoints, midpoint and dividing nodes used to measure callosal thickness.

significantly. Two-group comparisons were undertaken with $t$-tests, and localisation for individual slice differences again using step-down testing. Non-parametric regression analyses using multiple dependent variables were undertaken to determine the effect of medication dose and positive and negative symptoms on callosal thickness measures. Statistical inference was based on the family-wise error rate method to correct for multiple comparisons. ${ }^{21}$

\section{Results}

\section{Demographic and illness data}

Comparison of the established illness, first-episode and control groups (see online Table DS1) demonstrated significant differences in gender $\left(\chi^{2}=9.68, P<0.01\right)$ with an excess of males with established illness compared with other groups, and age $\left(F_{(2,216)}=53.80, P<0.001\right)$ with first-episode $<$ controls $<$ established illness. Premorbid IQ differed significantly across groups $\left(F_{(2,216)}=6.48, \quad P<0.005\right)$ with controls $>$ first-episode=established illness. There were no significant differences across groups in handedness $\left(\chi^{2}=5.13, P=0.274\right)$ or height $\left(F_{(2,216)}=0.188\right.$, $P=0.829)$. Mean duration of illness prior to first scan in the established illness group was 13.30 years (s.d.=8.95), and in the firstepisode group the duration of their index psychotic episode prior to first scan was 64.20 days $($ s.d.=112.22). The age at onset of psychosis did not differ between the two broad patient groups ( $t=1.264, P=0.208)$. The PANSS negative symptom total score was higher in the established illness group at a trend level ( $t=1.741, P=0.084$ ), although positive symptoms did not differ $(t=-1.634, P=0.105)$. Medication dosage was significantly higher in the established illness group $(t=7.346, P<0.0001)$. When the three first-episode groups were compared, there were no significant differences on any demographic, medication, illness onset/duration variables or symptom variables, other than PANSS positive symptoms which were lower in the first-episode schizophrenia group $\left(F={ }_{(2,73)}=6.683, P=0.002\right)$.

\section{Analysis 1: main groups}

Total area of the corpus callosum did not differ significantly between the three main groups $\left(F_{(2,216)}=1.094, P=0.337\right)$, nor when analyses were limited to males and right-handers. Illness duration was not associated with area in the established illness group $(r=-0.052, P=0.638)$. Females across the sample had larger callosal area $\left(675.94 \mathrm{~mm}^{2}\right)$ than males $\left(648.76 \mathrm{~mm}^{2}\right)$, although this did not reach significance $(P=0.076)$. A significant group $\times$ gender effect was found $\left(F_{(6,216)}=3.238, P=0.041\right)$ with females $\left(715.44 \mathrm{~mm}^{2}\right)$ having a significantly larger total area than males $\left(640.70 \mathrm{~mm}^{2}\right)$ only in the control group $\left(F_{(1,54)}=6.028\right.$, $P=<0.05)$. When left-, right- and mixed-handed groups were 
examined, corpus callosum area did not differ overall $\left(F_{2,216)}=0.710, P=0.493\right)$, although a significant group $\times$ handedness effect was found $\left(F_{(6,216)}=3.335, P=0.038\right)$. Although in the control group left-handed people had a larger callosal area than right-handed people, this difference was not seen in the patient groups. There was no gender $\times$ handedness effect (by group) on area. Group differences were apparent in the length $\left(F_{(2,216)}=3.844, \quad P=0.023\right)$, curvature $\left(F_{(2,216)}=6.871, \quad P=0.001\right)$ and mean width $\left(F_{(2,216)}=3.685, P=0.026\right)$ of the callosum however, with patients with established illness having longer, thinner and more angulated callosi than the other two groups, which were comparable.

When comparing regional callosal thickness across groups, a number of differences were found. Across the three main groups (Fig. 2), a main effect of group was found $(P<0.0001)$ at slices 1-5 (anterior genu) and 29-30 (isthmus) which remained significant when age was controlled for $(P<0.05)$ or when only males were analysed $(P<0.001)$. In step-down comparisons, significantly smaller widths were seen in the established illness group compared with the control group at slices 1-5, 11-21 and 28-30 $(P=0.0005)$; and in the first-episode group as a whole at slices 1-3 $(P<0.005)$. Identical regional changes were seen in the male only cohort.

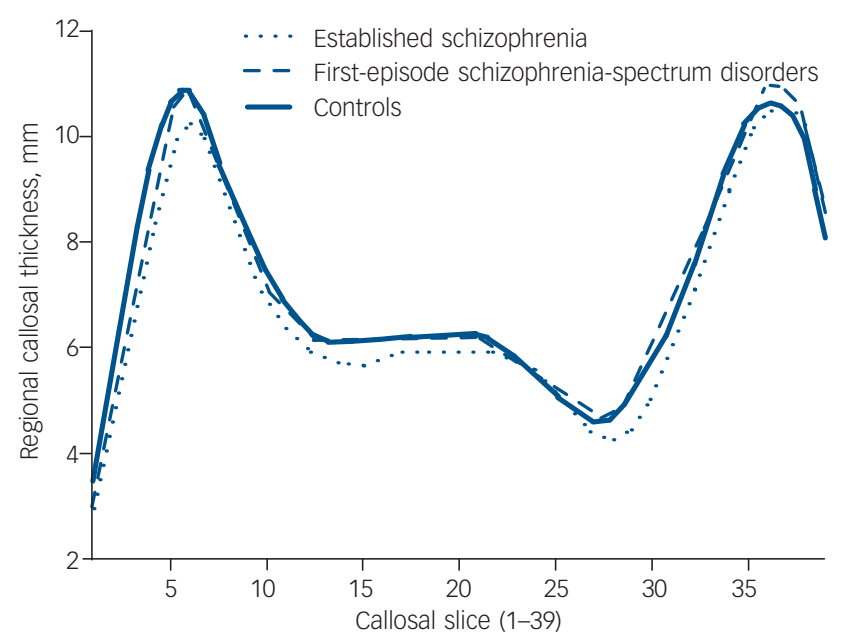

Fig. 2 Regional callosal thickness by main diagnostic group.

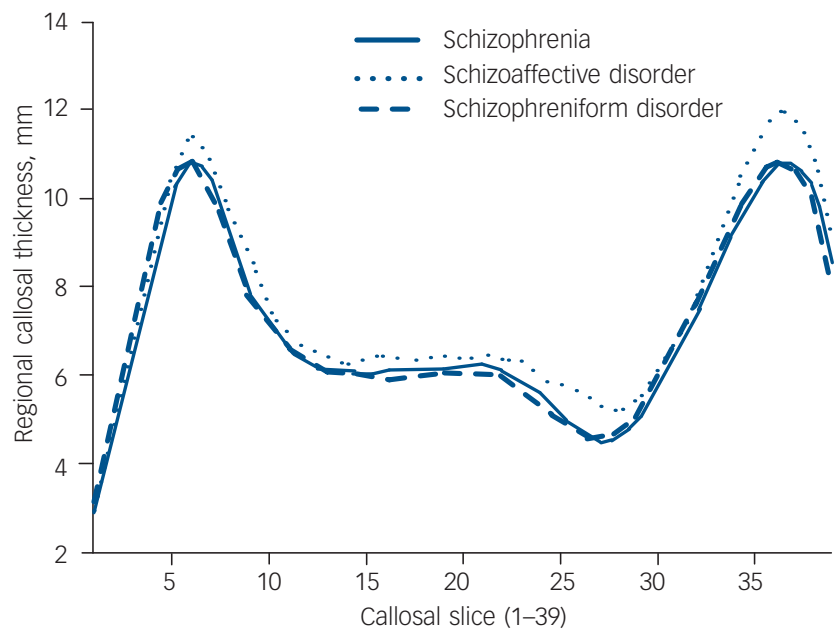

Fig. 3 Regional callosal thickness in first-episode subgroups.
To examine differences in corpus callosum thickness across illness stages, the two patient groups (first-episode and established illness) were compared. When the established illness group was compared with the first-episode group, the established illness group had significantly smaller widths in slices $13-17$ and $27-32$ $(P<0.05)$.

\section{Analysis 2: first-episode subgroups}

The three first-episode subgroups did not differ significantly on measures of callosal area $\left(F_{(1,75)}=1.429, P=0.246\right)$, curvature $\left(F_{(1,75)}=1.927, P=0.153\right)$, length $\left(F_{(1,75)}=0.103, P=0.902\right)$ and mean thickness $\left(F_{(1,75)}=1.690, P=0.192\right)$. When regional callosal thickness was compared between groups, there was no overall effect of group (Fig. 3, $P=0.145$ ). When first-episode subgroups were compared with the control group, only when the schizophrenia group was compared was an effect of group found $(P<0.05)$, with significant reductions seen in slices 3 and 4 , located in the genu of the callosum; the schizophreniform $v$. control comparison, equally well-powered, showed no overall effect of group $(P=0.638)$. Interestingly, the schizoaffective disorder group showed a trend $(P=0.079)$ towards a group effect with a reduction seen in slice 3 , and exploratory post hoc analyses suggested significant $(P<0.05)$ increases in slices $25-27$ and 3639 , when compared with the control group.

\section{Analysis 3: age and duration of illness variables}

As previous authors had found a loss of age-related expansion of callosal area in people with first-episode schizophrenia, ${ }^{10}$ the relationship of age to callosal area was examined separately in each group (Fig. 4). This relationship was seen in the control group $(r=0.297, P<0.05)$, but not in the established illness group ( $r=-0.050, \quad P=0.648)$, and this difference was significant $(P<0.05)$; the first-episode group's narrow age range prevented meaningful comparisons.

When callosal shape was investigated through examination of callosal slice thickness, no age $\times$ group interaction was found $(P=0.232)$. When examining the effect of age on regional callosal thickness, in the healthy control sample, an expansion was seen in nodes 38 and 39 with age $(P<0.05)$, not seen in the established illness group. However, the established illness group showed a reduction with age in nodes $30-32(P<0.01)$; of note, a trend towards an effect of duration of illness was seen in this region, in nodes $30-31(P=0.078)$.

\section{Analysis 4: medication dosage}

Complete medication data at scanning time were available for $66 /$ 86 patients with established illness (28 on typical and 36 on atypical antipsychotics and 2 on no medication) and for $72 / 76$ patients with first-episode schizophrenia-spectrum disorders (27 on typicals, 43 on atypicals and 2 on no medication). There was no difference in any demographic measure (age/gender/height/ premorbid IQ) between those on typical $v$. atypical antipsychotics, and no difference in the main callosal measures (area, length, curvature and thickness) across and within the established illness and first-episode groups. Removing patients on lithium treatment $(n=3)$ did not affect the results.

Medication dosage in chlorpromazine equivalents did not affect any of the main callosal measures, although it negatively correlated with curvature alone $(r=-0.357, P=0.007)$ in the first-episode group. In the regression analysis, medication dose was not significantly related to regional slice thickness in the first-episode or established illness groups. 


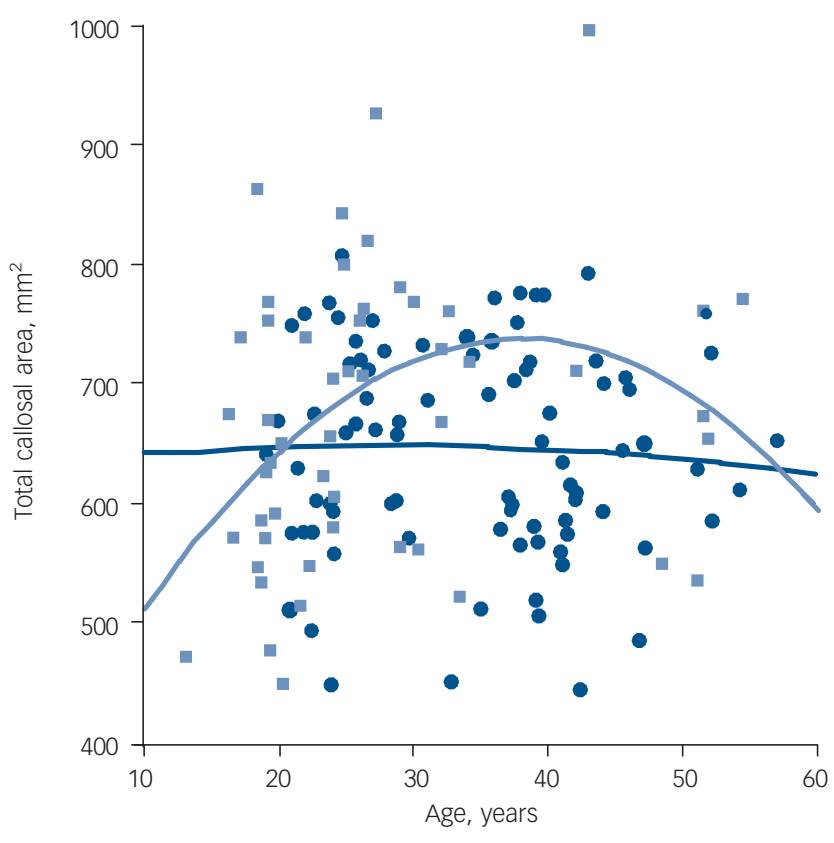

Fig. 4 Callosal area between groups according to age.

Light blue, control group; dark blue, established illness group. tive relationship with total callosal size and mean thickness that was not present in established illness.

\section{Regional thickness changes}

Regional thickness of the corpus callosum has not been examined in other cohorts using a method like that described in this study. The most similar method of analysis was a study by Downhill et $a l^{22}$ comparing controls, patients with schizophrenia and patients with schizotypal personality disorder, dividing the callosum into 30 segmental areas (not widths) based on equidistant nodes along a mid-callosal spline and using repeated-measures ANOVA. This study found a smaller area in both the genu and splenium of patients with schizophrenia; findings in the genu are consistent with our findings. Their research did not assess a first-episode group but did include a schizotypy comparator group. The advantage of using computational morphometry is that it avoids the arbitrary distinction of the corpus callosum into defined subregions, such as the method defined by Witelson, ${ }^{23}$ and ensures that the methodology is free of arbitrary anatomicalassumptions that may alter the results. Additionally, a methodology that uses a large number of subdivisions or slices increases the potential of detecting subtle regional changes, and rigorous non-parametric methods for statistical inference allow correction for multiple comparisons and dependence of adjacent slice measurements.

\section{Changes at illness stage}

In addition, no other study has examined callosal morphology using patients with first-episode psychosis/schizophrenia or chronic schizophrenia using the same methodology. As the findings in patients with first-episode schizophrenia-spectrum disorders and with established illness were homologous in anterior regions, a similar process may be involved in causing the regional reductions in the genu of the corpus callosum in both groups, indicating that anterior pathology is present at first episode of illness. Chronic schizophrenia shows similar reductions in the anterior genu (slices 2-5, carrying ventral/medial prefrontal fibres), with additional reductions in posterior genu/anterior body (slices 13-17, carrying cingulate, premotor and supplementary motor area fibres) and isthmus (slices 27-32, carrying cingulate, superior temporal and posterior parietal fibres). ${ }^{24}$ It may be these changes outside the anterior genu that are related to a subgroup who develop chronic illness, whereas changes in the genu that occur with or prior to first episode of psychosis may reflect an earlier neurodevelopmental insult present across subgroups, or changes that occur during first psychosis. A second possibility is that these changes represent illness progression; however, longitudinal analysis in the same individuals is needed to demonstrate the presence of 'neuroprogressive' change conclusively. ${ }^{25}$ Examining individuals pre-psychosis who later progress to psychosis would allow a determination of the timing of the onset of these changes.

The subgroup analysis of the first-episode group identified anterior reductions in the schizophrenia and schizoaffective disorder subgroups, but not the schizophreniform subgroup. Assuming that the schizophreniform subgroup differs from the schizophrenia subgroup only in duration of symptoms, this raises the possibility that the genual changes seen actually occur during the first psychotic episode rather than prior to it. Furthermore, since only the schizoaffective disorder subgroup showed expansions in other callosal regions, the results may suggest that the affective axis of this illness is associated with changes in other brain regions. We also mirrored the results of Keshavan et al in showing a loss of the normal age-related expansion of corpus 
callosum area in schizophrenia, ${ }^{10}$ although this finding contrasts with that of Woodruff et al, who showed a loss of the negative correlation between age and corpus callosum area in patients. ${ }^{26}$

The corpus callosum is topographically organised, with anterior segments connecting anterior cortical regions and posterior segments connecting posterior cortical regions. ${ }^{24}$ In Alzheimer's disease, patients with dementia and in the predementia phase show reductions in callosal regions associated with cortical hypometabolism and atrophy; ${ }^{27}$ it could be expected that alterations in cortical regions seen in schizophrenia in prefrontal, temporal and inferior parietal $\operatorname{cortex}^{28}$ would be associated with regional changes in the callosal genu, isthmus and anterior splenium. Shape analysis of the corpus callosum has implicated these regions in patients with first-episode schizophrenia. ${ }^{29}$ This suggests that not only are these changes present at the first episode of schizophrenia and thus potentially representative of neurodevelopmental changes, but that they may relate to grey matter changes - although studies examining both cortical regions and callosal subregions are lacking. Previous studies of the corpus callosum in schizophrenia have been limited by small sample sizes (the mean number of patients was 25 and of controls was 17 in studies prior to Woodruff's 1995 meta-analysis) ${ }^{9}$ and many studies have not controlled for factors known to affect corpus callosum size and shape, including gender, handedness and age. ${ }^{23}$ In addition, as antipsychotic medication has been shown to produce increases and decreases in regional white matter volume $^{30}$ and may confound longitudinal studies or those that aim to compare individuals at different illness stages, ${ }^{31}$ the possible effect of medication is an important potential confounder on corpus callosum structure, not yet examined in morphometry studies. Examining patients across the life-cycle of schizophrenia may shed light on the neurodevelopmental timing of a potential neuropathological process ${ }^{25}$ and may provide insights about the relationship of brain changes to prognosis.

\section{Relevance of white matter changes}

This study leaves a number of unanswered questions. The first of these is whether callosal changes are primary or secondary to grey matter changes that have been reported in studies of individuals who are pre- or peri-psychotic. A compelling body of neuroimaging evidence exists implicating white matter structures, including the corpus callosum, in schizophrenia, ${ }^{32-34}$ but most of these studies have not examined related grey matter structures in unison in the way that studies of other neurodegenerative disorders, such as Alzheimer's disease, have. ${ }^{27}$ Alterations in either compartment may produce changes in the other; for example, loss or reduction of cortical neurons will result in a reduced number of inter-hemispheric axons, whereas impaired myelination and thus conduction can result in changes in neuronal size and local connectivity. ${ }^{32}$ We cannot comment on the diagnostic specificity of these changes, as patients with bipolar disorder have also been described as showing reductions in the genu and isthmus, ${ }^{35}$ more work is needed, including direct comparison between patients with chronic schizophrenia and bipolar disorder using the same methodology.

Owing to the limitations of volumetric MRI analysis, the alterations in regional size of the corpus callosum in schizophrenia in our study do not allow the determination of the underlying neuropathological changes. A reduction in volume may represent a reduction in number of axons, size of axons or a reduction in their myelin sheaths (thus increasing the density of axons). Aboitiz et al first demonstrated in healthy controls that variance in area was generally the result of alterations to number rather than density of interhemispheric fibres, but only those small-diameter fibres that connect association cortices; ${ }^{36}$ thus, it may be that regional reductions in genu and isthmus in our study represent a decreased number of inter-hemispheric fibres connecting association cortices. In addition, a negative correlation exists between lateralisation and total fibre number, such that greater hemispheric asymmetry results in a reduced number of callosal fibres; ${ }^{37}$ the greater loss of callosal area in female than in male patients with psychosis in our study could suggest a reduction of gender-specific lateralisation, consistent with studies positing a loss of asymmetry in both grey matter ${ }^{38}$ and white matter ${ }^{39}$ structures in schizophrenia. Fibre number also decreases with age, ${ }^{40}$ and age $\times$ gender interactions, already described for regional callosal volume, have been reported for fibre numbers in the corpus callosum in healthy individuals ${ }^{41}$ and in people with schizophrenia. ${ }^{40}$ Some evidence for an alternative explanation (that reduced callosal size is secondary to reduced myelination) comes from studies examining signal intensity in callosal white matter, an index of myelination; reduced signal intensity has been shown in schizophrenia and bipolar disorder, but not in major depression or other psychiatric disorders. ${ }^{42,43}$ Thus, one explanation for our findings is an interaction between the development of psychotic illness and normal neurodevelopment on corpus callosum fibre number and/or myelination.

\section{Conclusions}

Our findings suggest that the corpus callosum in schizophrenia differs significantly in shape from that in healthy individuals, and that some of these changes are present or occur during the first episode of psychosis. The relationship between findings of changes in white matter regions that connect grey matter structures previously demonstrated to show neuropathological and volumetric change in schizophrenia is intriguing, but these findings alone do not allow elucidation of which of these pathologies may be primary, or whether they occur in concert. Longitudinal studies that elucidate the temporal relationship between white and grey matter change are necessary to shed light on causal relationships, if any, between changes in these two compartments of the central nervous system in schizophrenia.

\footnotetext{
Mark Walterfang, FRANZCP, Melbourne Neuropsychiatry Centre, Department of Psychiatry, University of Melbourne, and North Western Mental Health Program, Sunshine Hospital and Royal Melbourne Hospital, Melbourne; Amanda G. Wood, PhD, David C. Reutens, MD, FRACP, Department of Medicine (Neurosciences), Southern Clinical School, Monash University, Melbourne; Stephen J. Wood, PhD, Melbourne Neuropsychiatry Centre, Department of Psychiatry, University of

Melbourne, and North Western Mental Health Program, Sunshine Hospital and Roya Melbourne Hospital; Jian Chen, ME, Department of Medicine (Neurosciences), Southern Clinical School, Monash University, Melbourne; Dennis Velakoulis, FRANZCP, Melbourne Neuropsychiatry Centre, Department of Psychiatry, University of Melbourne, and North Western Mental Health Program, Sunshine Hospital and Royal Melbourne Hospital; Patrick D. McGorry, FRANZCP, ORYGEN Research Centre, Early Psychosis Prevention and Intervention Centre (EPPIC), Personal Assistance and Crisis Evalaution (PACE) Clinic, and Department of PSychiatry, University of Melbour Christos Pantelis, MD, FRANZCP, Melbourne Neuropsychiatry Centre, Department of Psychiatry, University of Melbourne, and North Western Mental Health Program, Sunshine Hospital and Royal Melbourne Hospital, Melbourne, Australia
}

Correspondence: Mark Walterfang, Melbourne Neuropsychiatry Centre, Department of Psychiatry, University of Melbourne, Melbourne, VI 3050, Australia. Email: mark.walterfang@mh.org.au

First received 7 Jun 2007, final revision 30 Sep 2007, accepted 20 Nov 2007

\section{Acknowledgements}

This research was supported by project grants from the National Health and Medical Research Council (NHMRC; grant ID numbers: 970598 and 981112), lan Potter Foundation, Woods Family Trust, and a program grant from the Victorian Health Promotion Foundation. Woods Family Trust, and a program grant from the Victorian Health Promotion Foundation.
M.W. was supported by a Stanley Research Centre Grant. A.W. was supported by an NHMRC Clinical Research Training Fellowship (251755). S.W. was supported by an NHMRC 
Clinical Career Development Award. S.W., C.P., D.V. and P.MCG. were supported by an NHMRC Programme Grant (350241). P.MCG. was supported by a National Alliance for Research on Schizophrenia and Depression Distinguished Investigator Award. M.W. takes responsibility for the integrity of the data and the accuracy of the data analysis. All authors had full access to all the data in the study.

\section{References}

1 David A. Schizophrenia and the corpus callosum: developmental, structural and functional relationships. Behav Brain Res 1994; 64: 203-11.

2 Swayze V, Andreasen N, Erhardt J, Yuth W, Alliger R, Cohen J. Developmental abnormalities of the corpus callosum in schizophrenia. Arch Neurol 1990; 47: 805-8.

3 Nasrallah HA, Andreasen NC, Coffman JA, Olson SC, Dunn VD, Ehrhardt JC, Chapman SM.. A controlled magnetic resonance imaging study of corpus callosum thickness in schizophrenia. Biol Psychiatry 1986; 21: 274-82.

4 Jacobsen LK, Giedd JN, Rajapakse JC, Hamburger SD, Vaituzis AC, Frazier JA Lenane MC, Rapoport JL. Quantitative magnetic resonance imaging of the corpus callosum in childhood onset schizophrenia. Psychiatr Res 1997; 68 77-86.

5 Bachmann S, Pantel J, Flender A, Bottmer C, Essig M, Schroder J. Corpus callosum in first-episode patients with schizophrenia - a magnetic resonance imaging study. Psychol Med 2003; 33: 1019-27.

6 Woodruff P, Pearlson G, Geer M, Barta P, Chilcoat H. A computerized magnetic resonance imaging study of corpus callosum morphology in schizophrenia. Psychol Med 1993; 23: 45-56.

7 Günther W, Petsch R, Steinberg R, Moser E, Streck P, Heller H, Kurtz G, Hippius $\mathrm{H}$. Brain dysfunction during motor activation and corpus callosum alterations in schizophrenia measured by cerebral blood flow and magnetic resonance imaging. Biol Psychiatry 1991; 29: 535-55.

8 Meisenzahl EM, Frodl T, Greiner J, Leinsinger G, Maag KP, Heiss D, Hahn K, Hegerl U, Möller HJ. Corpus callosum size in schizophrenia: a magnetic resonance imaging analysis. Eur Arch Psychiatry Clin Neurosci 1999; 249 305-12.

9 Woodruff P, McManus I, David A. Meta-analysis of corpus callosum size in schizophrenia. J Neurol Neurosurg Psychiatr 1995; 58: 457-61.

10 Keshavan MS, Diwadkar VA, Harenski K, Rosenberg DR, Sweeney JA Pettegrew JW. Abnormalities of the corpus callosum in first episode treatment naive schizophrenia. J Neurol Neurosurg Psychiatr 2002; 72 757-60

11 American Psychiatric Association. Diagnostic and Statistical Manual of Mental Disorders (3rd edn, revised) (DSM-III-R). APA, 1987.

12 McGorry P, Singh B, Copolov D, Kaplan I, Dossetor C, Van Riel R. The Royal Park multi-diagnostic instrument for psychosis. Part II: development, reliability and validity. Schizophr Bull 1990; 16: 517-36.

13 First $\mathrm{M}$, Spitzer $\mathrm{R}$, Gibbon $\mathrm{M}$, Williams J. Structured Clinical Interview for DSM-IV Axis I Disorders (SCID-I), Clinician Version. American Psychiatric Publishing, 1997

14 Velakoulis D, Wood SJ, Wong MT, McGorry PD, Yung A, Phillips L, Smith D, Brewer W, Proffitt T, Desmond P, Pantelis C. Hippocampal and amygdala volumes according to psychosis stage and diagnosis: a magnetic resonance imaging study of chronic schizophrenia, first-episode psychosis and ultrahigh risk individuals. Arch Gen Psychiatry 2006; 63: 139-49.

15 Kay S, Opler L, Lindenmayer J. The Positive and Negative Syndrome Scale (PANSS): rationale and standardisation. Br J Psychiatry 1989; 155: 59-67.

16 Smith S. Fast robust automated brain extraction. Hum Brain Mapp 2002; 17 143-55

17 Woods R, Grafton S, Holmes C, Cherry S, Mazziotta J. Automated image registration I: general methods and intrasubject, intramodality validation. J Comp Assist Tomog 1998; 22: 155-65.

18 Otsu N. A threshold selection method from gray level histograms. IEEE Trans SMC 1979; 9: 62-6.

19 Nelson HE. National Adult Reading Test (NART) Test Manual. nferNelson, 1982

20 Holmes A, Blair R, Watson J, Ford I. Nonparametric analysis of statistic images from functional mapping experiements. J Cereb Blood Flow Metab 1996; 16: 7-22.

$21 \mathrm{Holm} \mathrm{S}$. A simple sequentially rejective multiple test procedure. Scand J Statist 1979; 6: 65-70.

22 Downhill JE Jr, Buchsbaum MS, Wei T, Spiegel-Cohen J, Hazlett EA Haznedar MM, Silverman J, Siever L. Shape and size of the corpus callosum in schizophrenia and schizotypal personality disorder. Schizophr Res 2000; 42: 193-208.

23 Witelson S. Hand and sex differences in the isthmus of the corpus callosum in schizophrenia: a post-mortem morphological study. Brain 1989; 112: 799-835.

24 Pandya D, Seltzer B. The topography of commisural fibers. In Two Hemispheres, One Brain: Functions of the Human Corpus Callosum (eds F Lepore, M Pitto, H Jasper): 47-73. Alan R Liss, 1986.

25 Pantelis C, Yücel M, Wood SJ, Velakoulis D, Sun D, Berger G, Stuart GW, Yung A, Phillips L, McGorry PD. Structural brain imaging evidence for multiple pathological processes at different stages of brain development in schizophrenia. Schizophr Bull 2005; 31: 672-96.

26 Woodruff $\mathrm{P}$, Phillips M, Rushe T, Wright I, Murray R, David A. Corpus callosum size and interhemispheric function in schizophrenia. Schizophrenia Res 1997; 23: 189-96.

27 Teipel SJ, Hampel H, Pietrini P, Alexander GE, Horwitz B, Daley E, Möller HJ, Schapiro MB, Rapoport SI. Region-specific corpus callosum atrophy correlates with the regional pattern of cortical glucose metabolism in Alzheimer disease. Arch Neurol 1999; 56: 467-73.

28 Pearlson G. Superior temporal gyrus and planum temporale in schizophrenia: a selective review. Prog Neuropsychopharmacol Biol Psychiatry 1997; 21: 1203-29.

29 DeQuardo JR, Keshavan MS, Bookstein FL, Bagwell WW, Green WD, Sweeney JA, Haas GL, Tandon R, Schooler NR, Pettegrew JW. Landmarkbased morphometric analysis of first-episode schizophrenia. Biol Psychiatry 1999; 45: 1321-8.

30 Christensen J, Holcomb J, Garver D. State-related changes in cerebral white matter may underlie psychosis exacerbation. Psychiatry Res 2004; 130: 71-8.

31 Dorph-Petersen K, Pierri J, Perel J, Sun Z, Sampson A, Lewis D. The influence of chronic exposure to antipsychotic medications on brain size before and after tissue fixation: a comparison of haloperidol and olanzapine in macaque monkeys. Neuropsychopharmacol 2005; 30: 1649-61.

32 Walterfang $M$, Wood S, Velakoulis D, Pantelis C. Neuropathological, neurogenetic and neuroimaging evidence for white matter pathology in schizophrenia. Neurosci Biobehav Rev 2006; 30: 918-48.

33 Davis KL, Stewart DG, Friedman JI, Buchsbaum M, Harvey PD, Hof PR, Buxbaum J, Haroutunian V. White matter changes in schizophrenia: evidence for myelin-related dysfunction. Arch Gen Psychiatr 2003; 60: 443-56.

34 Kubicki M, McCarley R, Shenton M. Evidence for white matter abnormalities in schizophrenia. Curr Opin Psychiatry 2005; 18: 121-34.

35 Brambilla P, Nicoletti MA, Sassi RB, Mallinger AG, Frank E, Kupfer DJ, Keshavan MS, Soares JC. Magnetic resonance imaging study of corpus callosum abnormalities in patients with bipolar disorder. Biol Psychiatry 2003; 54: 1294-7.

36 Aboitiz F, Scheibel A, Fisher R, Zaidel E. Fiber composition of the human corpus callosum. Brain Res 1992; 598: 143-53.

37 Aboitiz F, Scheibel A, Fisher R, Zaidel E. Individual differences in brain asymmetries and fiber composition in the human corpus callosum. Brain Res 1992; 598: 154-61.

38 Yücel M, Stuart GW, Maruff $P$, Wood SJ, Savage GR, Smith DJ, Crowe SF, Copolov DL, Velakoulis D, Pantelis C. Paracingulate morphologic differences in males with established schizophrenia: a magnetic resonance imaging morphometric study. Biol Psychiatry 2002; 52: 15-23.

39 Kubicki M, Westin CF, Maier SE, Frumin M, Nestor PG, Salisbury DF, Kikinis R, Jolesz FA, McCarley RW, Shenton ME. Uncinate fasciculus findings in schizophrenia: a magnetic resonance diffusion tensor imaging study. Am J Psychiatry 2002; 159: 813-20.

40 Highley J, Esiri M, McDonald B, Cortina-Borja M, Herron B, Crow T. The size and fibre composition of the corpus callosum with respect to gender and schizophrenia: a post-mortem study. Brain Lang 1999; 122: 99-110.

41 Aboitiz F, Rodriguez E, Olivares R, Zaidel E. Age-related changes in the fibre composition of the human corpus callosum: sex differences. Neuroreport 1996; 7: 1761-4.

42 Brambilla $P$, Nicoletti M, Sassi RB, Mallinger AG, Frank E, Keshavan MS Soares JC. Corpus callosum signal intensity in patients with bipolar and unipolar disorder. J Neurol Neurosurg Psychiatry 2004; 75: 221-5.

43 Diwadkar V, DaBellis M, Sweeney J, Pettegrew J, Keshavan M. Abnormalities in MRI-measured signal intensity in the corpus callosum in schizophrenia. Schizophr Res 2004; 67: 277-82. 